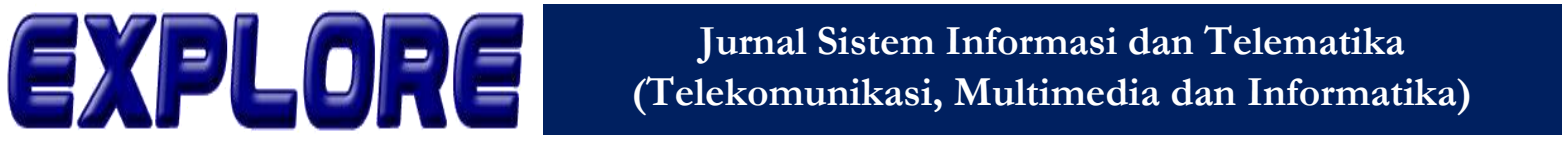

\section{Perancangan Data Warehouse Harga Pangan Di Wilayah Perumda Pasar Jaya}

\author{
Khoirun Nisa, Dedy Sugiarto, Teddy Siswanto \\ Program Studi Sistem Informasi \\ Universitas Trisakti \\ Jakarta, Indonesia \\ khoirun065001700019@std.trisakti.ac.id,dedy@trisakti.ac.id, teddysiswanto@trisakti.ac.id
}

\begin{abstract}
Abstrak-Perumda Pasar Jaya merupakan perusahaan umum daerah yang memiliki tanggung jawab dalam menjalankan operasi pasar di Wilayah DKI Jakarta untuk menjaga stabilitas harga pangan. Dalam menjaga stabilitas harga pangan diperlukan pengelolaan data agar ketika harga pangan mengalami kenaikan diatas Harga Eceran Tertinggi (HET) ataupun mengalami fluktuasi harga pangan, data tersebut dapat diakses dengan mudah. Tujuan penelitian ini ialah membuat suatu sistem pengolahan data harga pangan melalui proses perancangan data warehouse, sehingga digunakan sebagai salah satu komponen pengambilan keputusan di Perumda Pasar Jaya. Data yang dipakai ialah data komoditas bawang merah, bawang putih, cabai merah keriting, cabai rawit hijau, daging sapi has, dan daging sapi murni. Pengembangan rancangan data warehouse ini menggunakan metode Kimball. Data warehouse yang dibuat melalui tahapan cleansing data, penggabungan data tahun 2018 hingga 2020, pengkategorian data, dan Extract Transformation, Loading (ETL) dengan menggunakan Pentaho Data Integration (PDI) sehingga dapat dibangun database OLAP. Desain data warehouse dengan pendekatan pemodelan database multidimensi menggunakan tabel dimensi dan tabel fakta. Tabel dimensi yang dibuat yaitu tabel dimensi komoditi, pasar, dan waktu. Sedangkan tabel fakta berisi harga pangan dan harga eceran tertinggi. Data warehouse yang dibuat sudah memenuhi keinginan Perumda Pasar Jaya yang dijadikan bahan pendukung untuk membantu stabilitas harga pangan.
\end{abstract}

Kata Kunci: Data warehouse, Harga Pangan, Extract Transformation Loading (ETL), Pentaho Data Integration, Metode Kimball

\section{Pendahuluan}

Perumda Pasar Jaya memiliki tugas pokok dan fungsi yaitu merilis informasi terkait harga pangan di Wilayah DKI Jakarta secara langsung. Informasi tersebut disajikan dalam website Info Pangan Jakarta. Perumda Pasar Jaya mempunyai fokus yaitu dalam hal stabilitas pangan yang menjadi salah satu prioritas program pembangunan nasional, karena pangan mempunyai nilai strategis pada kebutuhan masyarakat yang paling mendasar serta dalam aspek stabilitas ekonomi, sosial, keamanan, dan politik. Pemanfaatan teknologi informasi yang terintegrasi dengan proses kerja di suatu lembaga atau korporasi telah menjadi kebutuhan mutlak saat ini. Hal ini disebabkan adanya kebutuhan lembaga untuk mengoptimalkan kemampuan menganalisis masalah yang dihadapi yang akan mempengaruhi proses pengambilan keputusan. Ketersediaan data yang lengkap dan akurat merupakan tolak ukur kelangsungan hidup perusahaan mupun lembaga.Karena Perusahaan Umum Daerah Pasar Jaya membutuhkan analisis, monitoring dan forecasting harga pangan sehingga kita harus merancang data warehouse harga pangan. Data terkait harga pangan yang dikelola meliputi data harga komoditas pangan di wilayah Perumda Pasar Jaya. Data-data tersebut dikelola untuk digunakan sebagai data yang akan ditampilkan di website
Info Pangan Jakarta. Data harga pangan dikelola dalam file Microsoft Excel yang merupakan hasil dari rekapan data harga di Wilayah Perumda Pasar Jaya. Perancangan data warehouse bertujuan untuk memasukkan data ke dalam database sebagai salah satu proses business intelligence. Karena masalah yang terjadi saat ini umumnya terletak pada ragamnya memasukkan data, menyebabkan keterlambatan dalam pemrosesan data. Penelitian ini diharapkan dapat mengatasi keberagaman sumber data dengan menggunakan Pentaho Data Integration-Kettle. Aplikasi ini dapat mengintegrasikan data yang ada untuk siap diolah di data warehouse sehingga nantinya dapat disajikan dengan akurat dan tepat waktu. Proses integrasi ini terkenal dalam Business Intelligence sebagai proses Extract, Transform, Loading (ETL). ETL akan mengubah data On-Line Transactional Processing (OLTP) menjadi Data On-Line Analytical Processing (OLAP).

Pada penelitian A D Barahama dan R Wadani menuliskan tentang jurnal "Data analysis and data warehouse design based on Penthao data integration (kettle) to support the determination of student learning achievement". Penelitian ini menggunakan tabel dimensi dan tabel fakta untuk design data warehouse yang diharapkan dapat membantu dalam memecahkan masalah, mengevaluasi hasil belajar dan 
mendukung pengambilan keputusan. Aplikasi yang dibuat dapat diintegrasikan datanya untuk di proses dalam data warehouse sehingga dapat di tampilkan dengan akurat dan satu waktu. Skema yang dipakai dalam penelitian tersebut yaitu Star Schema. Tabel yang dibuat yaitu 4 tabel dimensi dan 1 tabel fakta yang berisi data mahasiswa, data watu, data mata pelajaran, data nilai. Hasil dari penelitian tersebut menggunakan Pentaho Data Integration (kettle) memudahkan pihak sekolah karena menghasilkan informasi yang dapat dilihat dari tabel yang terkelola dengan baik sehingga lebih mudah untuk penentuan prestasi belajar siswa. Dari data tersebut digunakan untuk laporan dan informasi bagi sekolah yang dapat digunakan untuk mengevaluasi hasil belajar, dan mendukung pengambilan keputusan [1][2]. Penelitian Perancangan Data warehouse di Wilayah Perumda Pasar Jaya sama memakai model data warehouse star schema. Pada penelitian ini ditampilkan proses transformation dari setiap tabel dimensi dan tabel fakta, namun penelitian A D Barahama dan R Wadani hanya tabel dimensi siswa, tabel dimensi nilai serta tabel fakta. Penelitian terkait data warehouse ditulis oleh Ardhian Agung Yulianto, dan Yoshia Kasahara dengan judul penelitian "Data warehouse System for Multidimensional Analysis of Tuition Fee Level in Higher Education Institutions in Indonesia"pada tahun 2020. Penelitian ini mengembangkan sistem untuk memberikan informasi yang cukup kepada administrator untuk pengambilan keputusan biaya kuliah pelamar dengan mengintegrasikan data multisumber. Empat prosedur yang diterapkan dalam membangun sistem ini yaitu persiapan, integrasi, analisis, dan visualisasi. Data warehouse menunjukkan empat dimensi dasar yaitu (fakultas, tahun, jenis, peserta, dan tingkat biaya kuliah) di semua tujuh dimensi dan tiga data mengenai pelamar, tingkat biaya kuliah, dan status pembayaran. Tabel fakta pada penelitian ini dalam hal pengukuran bisnis untuk dianalisis, misalnya distribusi tingkat biaya kuliah dan persentase biaya kuliah. Sedangkan data dimensi mewakili descriptor konteks pengukuran. Model data warehouse yang dipakai yaitu Denormalized Multidimensional Facts Constellation Schema.

Berdasarkan studi kasus pada penelitian ini hasilnya menunjukkan bahwa teknologi data warehouse memungkinkan analisis multidimensi biaya kuliah. Analisis OLAP yang telah ditentukan sebelumnya meningkatkan kecepatan pemrosesan yang memungkinkan database operasional yang aman saat mengambil data historis elektronik. Hasil analisis disajikan dalam berbagai grafik dan dashboard tingkat biaya kuliah yang memiliki banyak fungsi dalam memberikan wawasan relatif terhadap kinerja bisnis [3]. Namun Pada penelitian ini tidak disajikan dalam bentuk grafik maupun visualisasi karena data warehouse terkait data harga pangan info pangan Jakarta dipakai untuk di proses dalam pembuatan 3 level dari Bussiness Intelligent data harga pangan.

Penelitian terkait data warehouse lainnya yaitu Hilario, Manuel, Esenarro, Doris, Vega Hugo, Rodriguez Ciro dalam judul penelitian "Integration Of The Enterprise Information To Facilitate Decision Making”. Penelitian ini bertujuan untuk menerapkan Teknik Bussiness Intellijen untuk mengambil keuntungan dari kondisi sistem yang ada dan meningkatkan kemampuan berbiaya rendah dalam ekstract, transformation, loading dengan snapshot yang mengintegrasikan informasi dari layanan web perusahaan. Metodologi dalam mengembangkan penelitian ini adalah HEFESTO, waktu pengembangan adalah satu minggu menerapkan agile methodologies, mencapai perkembangan singkat dengan terdefinisi dengan baik dan fase yang mudah dipahami dengan memakai tools Pentaho BI Suite menggunakan tools open source sehingga minim biaya yang dikeluarkan [4].

Nurcahyo, Khoirudin Eko, Sucipto, Nugroho Arie melakukan penelitian dengan judul "Mapping Student Data Using Data W arehouse for Promotion at Vocational High School of $Z$ '. Permasalahan dari penelitian ini yaitu pihak sekolah menyimpan data siswa dalam 2 (dua) aplikasi yang berbeda sehingga pihak sekolah memiliki kelsulitan dalam menganalisa data pendaftar, siswa tersebut berasal dari SMP mana saja dengan dilihat mana saja pendaftar yang paling sedikit ataupun paling banyak. Dengan dibuatnya data warehouse tersebut maka pihak sekolah dapat mengelola data siswa dengan baik dan mudah. Hasil dari penelitian ini dibuatnya Bussiness Intelligent berbasis web yang dimana web tersebut dapat di akses oleh user dengan melihat data data siswa berdasarkan jurusan, jenis kelamin, asal SMP, waktu pendaftaran, serta rekomendasi. Tabel dimensi yang dibuat pada penelitian ini adalah tabel dimensi rekomendasi, jenis kelamin, jurusan, sekolah, dan waktu. Tabel fakta yang dibuat dalam penelitian ini adalah tabel fakta pendaftaran. Pada penelitian ini menggunakan star schema karena dilihat dengan kasus yang dilakukan dinilai lebih sesuai.. Hasil pengolahan data yang dilakukan menunjukkan jurusan yang paling banyak pendaftarnya ialah jurusan perbankan sebanyak 457 siswa dan peminat yang paling sedikit dari jurusan tata busana sebanyak 209 pendaftar [5]. Dalam penelitian Perancangan Data Warehouse Data Harga Pangan di Wilayah Perumda Pasar Jaya menggunakan model schema yang sama dengan penelitian Nurcahyo Nurcahyo, Khoirudin Eko, Sucipto, Nugroho Arie yaitu star schema. Selain itu pada penelitian ini tidak adanya tampilan chart yang dihasilkan, dikarenakan dari hasil data warehouse tersebut akan dipakai pada proses implementasi Bussiness Intelligent yang akan menampilkan visualisasi 3 proses dari Bussiness Intelligent. Kelebihan dari penelitian Perancangan Data Warehouse Data Harga Pangan di Wilayah Perumda Pasar Jaya yaitu menampilkan isi data dari setiap tabel dimensi dan tabel fakta dan alur yang dijelaskan detail dari proses perancangan database OLAP, cleansing dan penggabungan menggunakan Pentaho Data Integration, ETL untuk pembuatan database OLAP.

\section{Dasar Teori}

A. Pangan

Pangan adalah salah satu dari fokus utama dalam program pembangunan nasional karena memiliki nilai strategis terhadap kebutuhan masyarakat yang paling mendasar serta aspek stabilitas ekonomi, stabilitas politik, ketahanan nasional, maupun stabilitas keamanan. Terkait aspek dalam ekonomi pangan, harga memiliki aspek yang paling penting dan perlu mendapatkan perhatian. Penentuan harga pada pangan sangat penting pada tingkat pelaku ekonomi di tingkat nasional dan daerah. 
Pada peningkatan ketahanan pangan merupakan prioritas utama dalam pembangunan nasional, karena pangan merupakan kebutuhan yang paling mendasar bagi masyarakat sehingga pangan sangat mempunyai peran penting dalam meningkatkan pertumbuhan ekonomi nasional. Ketahanan pangan diartikan sebagai terdistribusi dengan harga terjangkau bagi masyarakat. Sehingga ketahanan pangan mencakup tingkat rumah tangga maupun tingkat nasional [6].

Harga Pangan di setiap pasar memiliki harga yang berbeda-beda, dikarenakan pengaruh terhadap proses distribusi komoditas pangan ke area pasar. Dalam menjamin agar seluruh masyarakat dapat memperoleh pangan dalam jumlah dan kualitas yang memadai dan dengan harga yang terjangkau maka harus adanya sistem terdistribusi yang efisien. Pengelolaan dan kepedulian dalam hal kelancaran distribusi pada banyak daerah masih terbatas, sehingga diakibatkan terjadinya ketidakstabilan harga pangan dan pasokan dari pangan, yang mempunyai dampak adanya gangguan ketahanan pangan pada wilayah tersebut [7].

\section{B. Pengertian Olap}

Online Analytical Processing (OLAP) merupakan pendekatan secara cepat untuk memudahkan dalam analisis banyak dimensi atau multidimensi. OLAP adalah bagian dari Business Intelligence yang memiliki kaitan yang erat dengan relational dari database, reporting dan lain sebagainya.

Karakteristik utama dari Online Analytical Processing adalah :

1. Mendukung dalam pemanfaatan data warehouse yang memiliki data banyak dimensi (multidimensional).

2. Menyediakan dalam fasilitas drill-down agar memperoleh informasi secara detail, dan rol- up agar memperoleh agregat dalam multidimensi.
3. Menghasilkan dari perhitungan dan perbandingan.

4. Menyediakan fasilitas dari query interaktif dan analisis yang kompleks.

5. Menyajikan suatu hasil dalam bentuk angka yang dapat mudah untuk di mengerti, maupun penyajian grafik[8].

\section{Pengertian ETL (Extract, Transform dan Load)}

Extract, Transform dan Load secara sederhana merupakan suatu kumpulan dari proses untuk mengambil maupun memproses data dari satu atau banyak sumber sehingga menjadi sumber baru, yaitu seperti mengolah data OLTP menjadi OLAP [9]. Proses-prosesnya ialah sebagai berikut:

\section{Extract}

Proses-proses yang diperlukan untuk terhubung dengan berbagai macam sumber data, dan membuat data tersebut tersedia bagi proses- proses selanjutnya, dengan contoh mengambil data dari database, membaca file excel, membaca file dari XML, dan lain sebagainya [4].

\section{Transform}

Fungsi apa saja yang berfungsi untuk mengubah data yang masuk menjadi data yang dikehendaki. Transform adalah proses manipulasi terhadap data dari suatu sistem sumber ke format lain pada data warehouse atau pada data mart sehingga menjadikan sebuah informasi yang bermakna [10][11].

3. Load

Semua proses yang diperlukan dalam mengisi data ke target atau dapat dikatakan proses yang akan memindahkan data yang telah ditransformasikan sebelumnya ke data warehouse. Strategi loading ke integration layer dibagi menjadi dua, yaitu strategi loading bagi tabel dimensi dan strategi loading bagi tabel fakta [4][5].

\section{Metodologi}

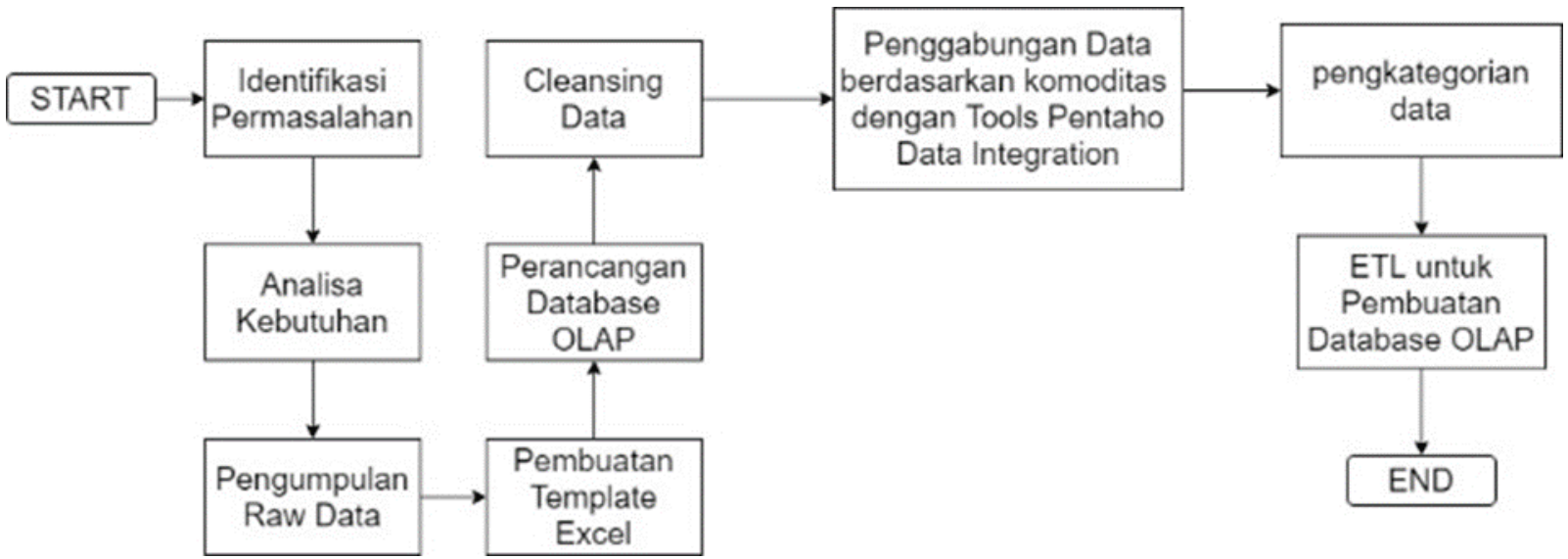

Gambar 1. Alur Penelitian

\section{A. Metode Pengumpulan Data}

Raw data merupakan data mentah atau dikenal dengan data primer hasil pencatatan peristiwa atau karakteristik dari suatu elemen yang dikumpulkan dari suatu sumber yang akan diolah menjadi suatu database OLAP dengan menggunakan Spoon Pentaho Data integration untuk toolsnya. Raw data yang diperoleh pada penelitian ini berasal 
dari Perusahaan Umum Daerah Pasar Jaya serta Data

Kementerian Perdagangan Republik Indonesia.

\section{B. Perancangan Database OLAP}

\begin{tabular}{|l|}
\hline \multicolumn{1}{|c|}{ DIM_WAKTU } \\
\hline $\begin{array}{l}\text { ID_WAKTU } \\
\text { WAKTU }\end{array}$ \\
\hline
\end{tabular}

\begin{tabular}{|l|}
\multicolumn{1}{|c|}{ DIM PASAR } \\
\hline ID_PASAR \\
NAMA_PASAR \\
\hline
\end{tabular}

DIM_KOMODIII

ID_KOMODITI

JENIS_KOMODITI

\begin{tabular}{l} 
Fact_Gabungan_HET_Komoditi \\
\hline ID_PASAR \\
ID_KOMODITI \\
ID_WAKTU \\
HARGA \\
\hline
\end{tabular}

Gambar 2. Daftar tabel dimensi dan tabel fakta

\section{Cleansing dan Penggabungan Data dengan} Tools Pentaho Data Integration (PDI)

Sesi selanjutnya ialah tahapan cleansing dan penggabungan data dengan menggunakan Tools Pentaho Data Integration (PDI). Pada tahapan cleansing ini untuk menghilangkan data yang tidak diperlukan dalam penelitian ini. Data yang dihilangkan pada penelitian ini adalah data minimal harga pangan, data maksimal harga pangan, 15 pasar yang tidak dipakai yaitu Pasar Anyer
Bahari, Pasar Gondangdia, Pasar Induk Kramat Jati, Pasar Kalibaru, Pasar Kalideres, Pasar Klender Ss, Pasar Koja Baru, Pasar Rawamangun, Pasar Pramuka, Pasar Pluit, Pasar Pulo Gadung, Pasar Pesanggrahan, Pasar Glodok, Pasar Matraman KK, dan Pasar Jatinegara.

Sedangkan pada tahap pengkategorian data dilakukan setelah tahap cleansing data berdasarkan periode tahun. Pengkategorian data ini berguna dalam hal menyesuaikan data yang tersedia dengan perancangan tabel dimensi dan tabel fakta yang telah dibuat sebelumnya.

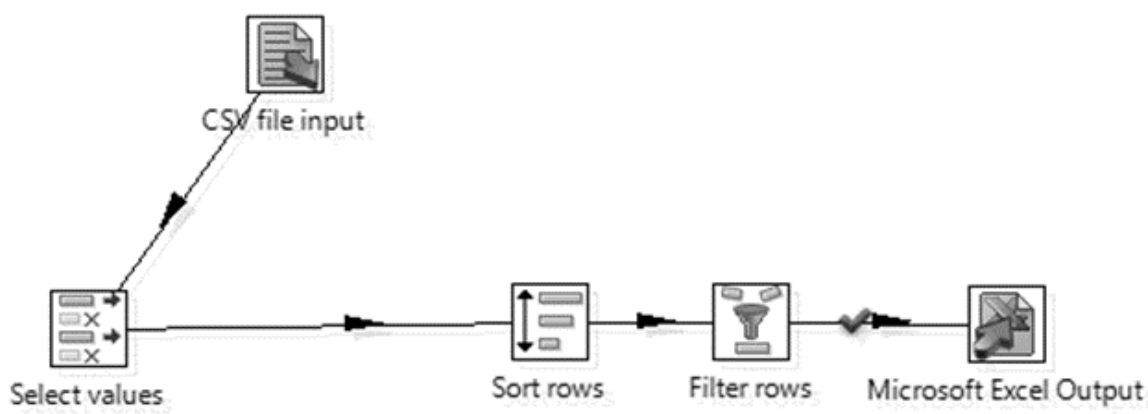

Gambar 3. Hop pada cleansing data harga pangan 

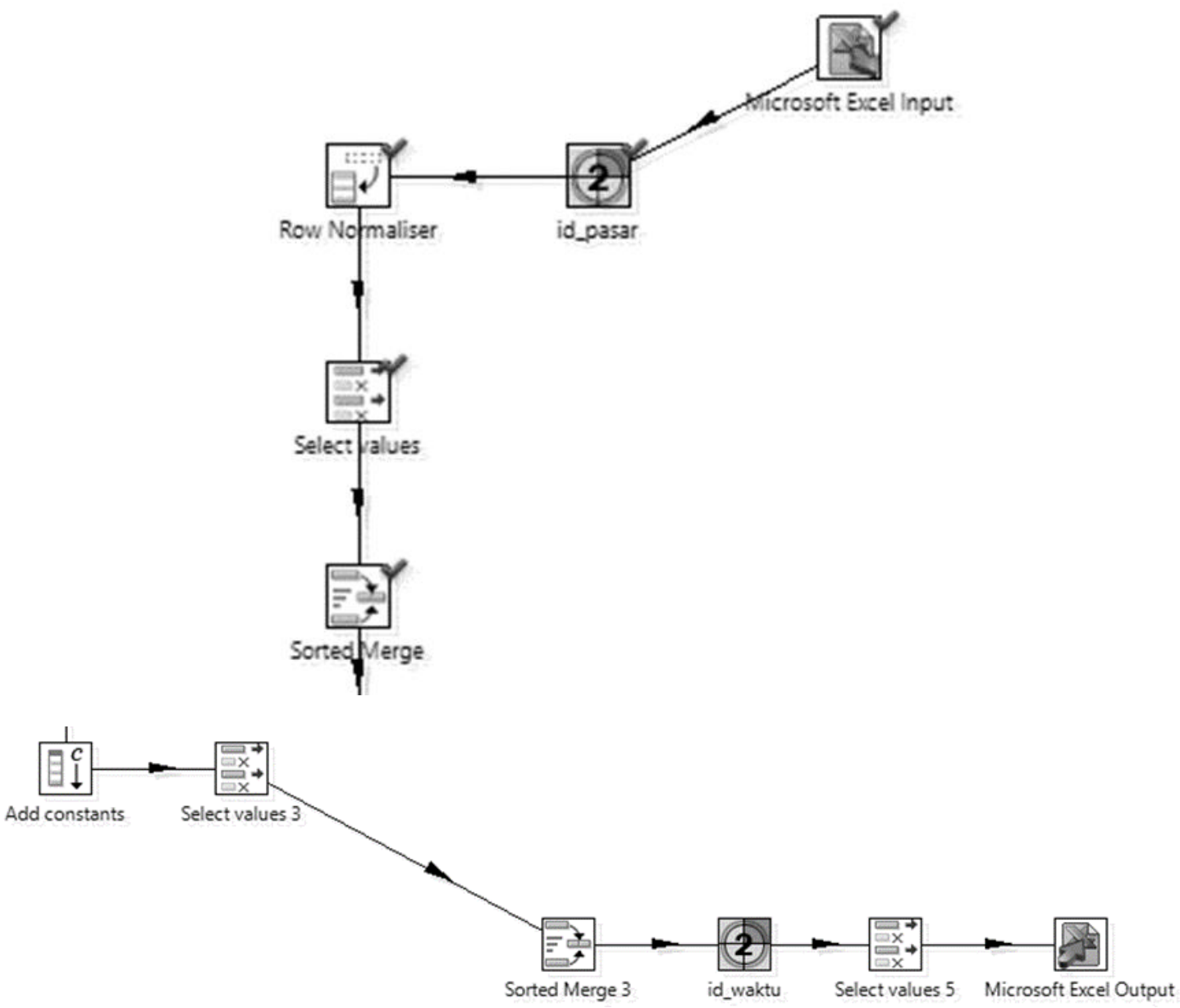

Gambar 4. Pengkategorian data harga pangan di pentaho data integration

\section{ETL untuk Pembuatan Database OLAP}

Pada tahap ini menggunakan tools Spoon Pentaho Data Integration untuk penginputan, mengekstrak data yang sudah di cleansing sebelumnya dan penggabungan data. Penyesuaian data yang tersedia agar kompatibel dengan database yang akan dibangun dalam penelitian ini dilakukan pada proses transform. Kemudian setelah itu dimasukkan atau biasa disebut dengan proses load ke dalam masing masing tabel dimensi maupun tabel fakta pada database PhpMyAdmin.
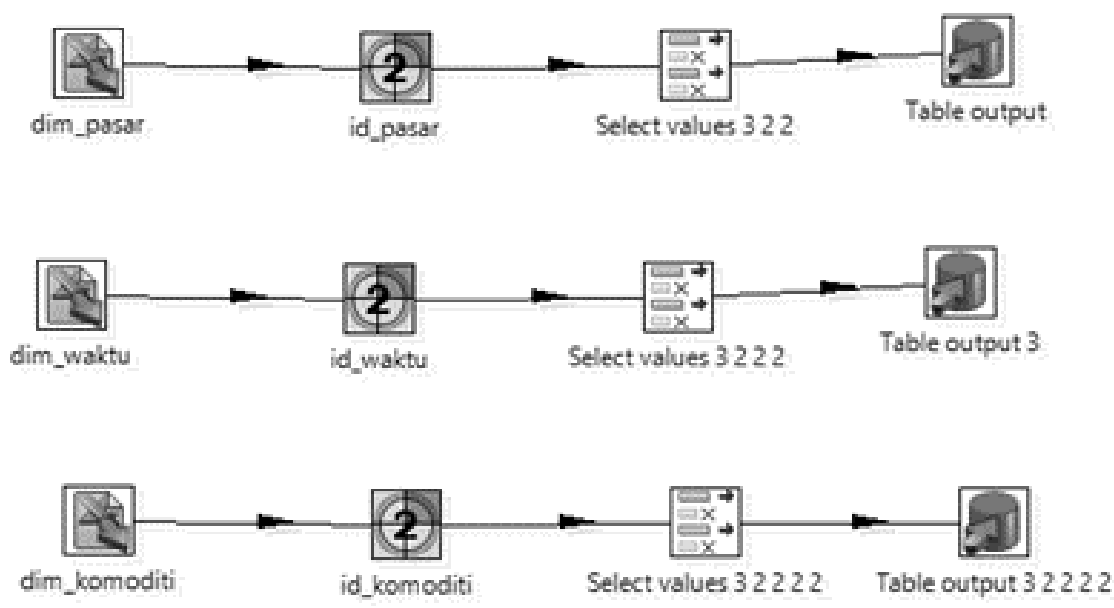

Gambar 5. Transformasi Demensi 


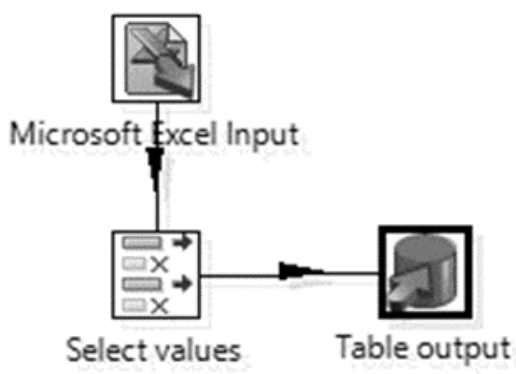

Gambar 6. Transformasi data harga pangan

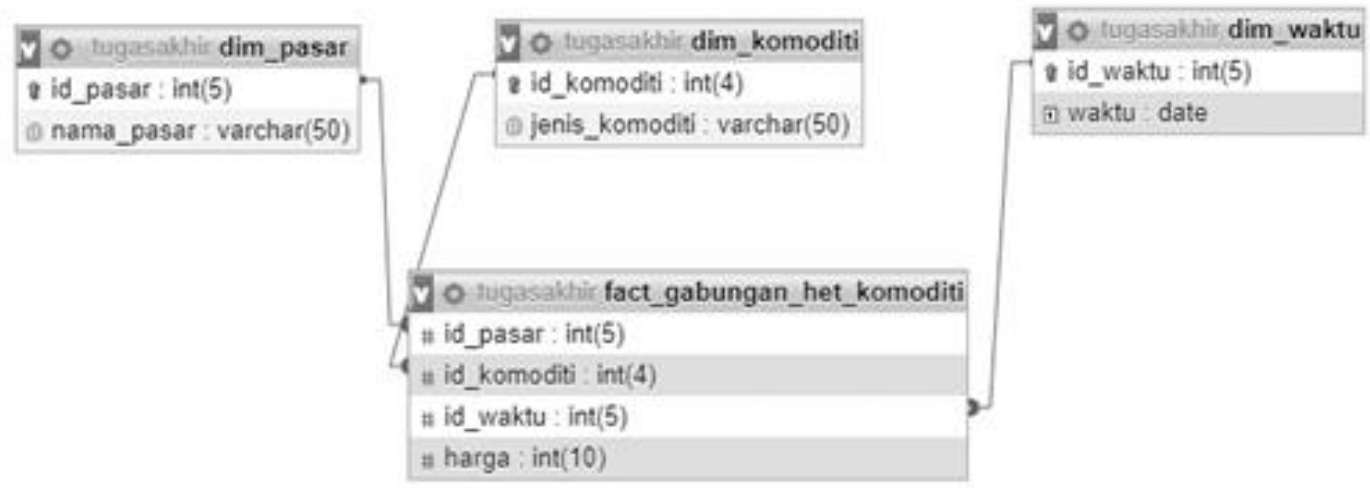

Gambar 7. Tabel relasi pada localhost phpmyadmin

\section{Hasil dan Pembahasan}

\section{A. Rancangan Database OLAP}

Untuk perancangan database OLAP terlebih dahulu membuat struktur dari tabel fakta dan struktur dari tabel dimensi pada database disertai atribut tipe data dan relasi antar tabel. Model dimensional untuk Tabel dimensi yang dipakai ialah Star Schema. Model tersebut dipilih karena cocok dengan data yang dimiliki. Tabel dimensi dan tabel fakta yang dirancang antara lain:

1. Tabel dimensi komoditi.

2. Tabel dimensi waktu.

3. Tabel dimensi pasar.

4. Tabel fakta harga pangan.

\section{B. Tabel Dimensi dan Tabel Fakta}

Pemodelan database multidimensi terdiri dari tabel fakta dan tabel dimensi dan saling berelasi. Skema sistem Online Analytical Processing (OLAP) merupakan dasar untuk melakukan data warehousing. Skema yang digunakan yaitu Star Schema. Star Schema dipilih karena dalam pembuatan data warehouse ini memiliki 1 tabel fakta dan 3 tabel dimensi sehingga dari susunan tabel yang dibuat membentuk bintang. Tabel dimensi berisi informasi yang bersifat kualitatif, sedangkan tabel fakta bersifat numerik (dalam bentuk angka). Isi dari tabel dimensi dan tabel fakta yaitu:

+ Opsi
$\leftarrow T \rightarrow$
$\square$ Ubah id_komoditi

Gambar 8. Tabel dimensi komoditi 


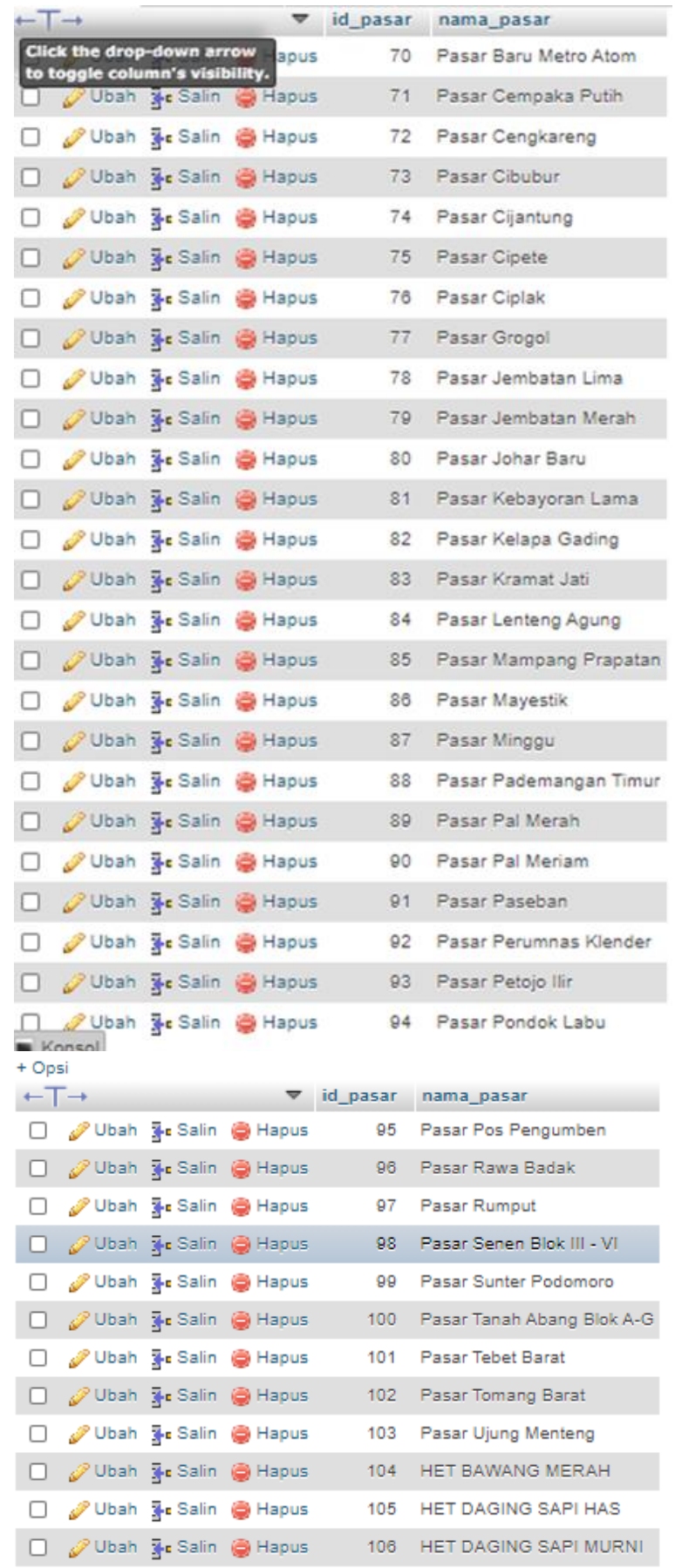

Gambar 9. Tabel dimensi pasar 


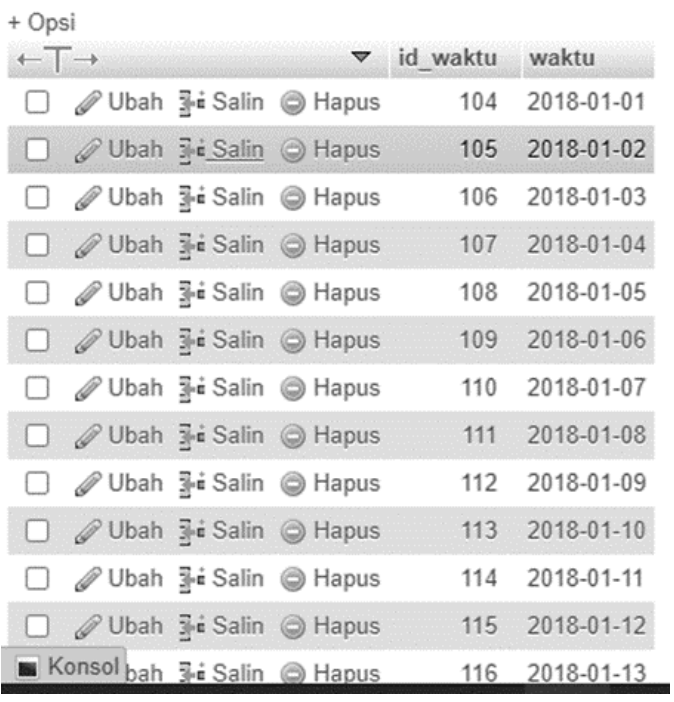

Gambar 10. Tabel dimensi waktu

\begin{tabular}{rrrr|}
$\begin{array}{r}\text { + Opsi } \\
\text { id_pasar }\end{array}$ & id_komoditi & id_waktu & harga \\
\hline 70 & 66 & 104 & 30000 \\
70 & 66 & 105 & 35000 \\
\hline 70 & 66 & 106 & 35000 \\
\hline 70 & 66 & 107 & 35000 \\
\hline 70 & 66 & 108 & 30000 \\
\hline 70 & 66 & 109 & 35000 \\
\hline 70 & 66 & 110 & 30000 \\
\hline 70 & 66 & 111 & 30000 \\
\hline 70 & 66 & 112 & 30000 \\
\hline 70 & 66 & 113 & 30000 \\
\hline 70 & 66 & 114 & 30000 \\
\hline 70 & 66 & 115 & 25000 \\
\hline 70 & 66 & 116 & 25000 \\
\hline Konsol & 66 & 117 & 25000 \\
\hline
\end{tabular}

Gambar 11. Tabel fakta harga pangan dan harga eceran tertinggi pangan

\section{Kesimpulan}

Dengan dibuatnya data warehouse harga pangan di wilayah Perusahaan Umum Daerah Pasar Jaya pada penelitian ini maka dapat membuat kesimpulan sebagai berikut:

1. Penggunaan metode Online Analytycal Processing (OLAP) membantu dalam hal integrasi data serta memiliki kemampuan pada sistem business intelligence untuk membaca data. Schema database yang dipakai adalah Star Schema.

2. Keberagaman data di Perusahaan Umum Daerah Pasar Jaya dapat diatasi dengan menggunakan Pentaho data Integration (PDI) - Kettle. Hasil perancangan data

3. Warehouse harga pangan dapat dilihat dalam bentuk tabel yang lebih tertib sehingga mudah untuk diproses.

4. Hasil data harga pangan yang awalnya dilakukan secara manual kini sudah menggunakan proses yang dibuat dalam menyimpan data ke dalam database sehingga memudahkan untuk pemindahan data.

\section{Daftar Pustaka}

[1] Barahama A D, dan Wardani R, "Data analysis and data warehouse design based on Pentaho data integration (kettle) to support the determination of student learning achievement." IOP Conference Series: Materials Science and Engineering. Vol 1098. No. 5. IOP Publishing, 2021

[2] Prasser F, Spengler H, Bild R, Eicher J, dan KuhnK A 2019 Privacy-enhancing ETL-processes for biomedical data Int. J. Med. Inform. 126 November 2018pp. 72-81

[3] Yulianto, Ardhian Agung, dan Yoshiya Kasahara. “ Data warehouse System for Multidimensional Analysis of Tuition Fee Level in Higher Education Institutions in Indonesia." IJACSA (International 
Journal of Advanced Computer Science and Application), vol. 11, no 6, 2020.

[4] Hilario, Manuel, Esenarro, Doris, Vega Hugo, Rodriguez Ciro. "Integration Of The Enterprise Information To Facilitate Decision Making.” Journal of Contemporary Issues in Business and Government Vol. 27, No. 1, 2021.

[5] Nurcahyo, Khoirudin Eko, Sucipto Sucipto, dan Arie Nugroho. "Mapping Student Data Using Data Warehouse for Promotion at Vocational High School of Z." Journal of Computer, Information System \& Technology Management Vol. 3, No 2 Oktober 2020.

[6] Saliem, H. Purwati, dan M. Ariani, "Ketahanan pangan, konsep, pengukuran dan strategi, ", FAE, vol. 20, no. 1, Juli., 2016.

[7] K. Nainggolan, "Ketahanan dan stabilitas pasokan, permintaan, dan harga komoditas pangan." Analisis Kebijakan Pangan, Vol. 6, No. 2, Juni. 2016.

[8] R. Akbar, dkk, "Analisis Data Penjualan Perusahaan Detergen XYZ dengan Aplikasi Zoho Reporting
Menggunakan Metode OLAP (Online Analytycal Processing)." JEPIN (Jurnal Edukasi dan Penelitian Informatika), vol. 3 , no. 1, pp. 71 -

75, 2017

[9] AMINE, Abdellah, Rachid AIT DAOUD, dan Belaid BOUIKHALENE, "Perfomance and analyses using two ETL extraction software solutions." IJOA (Internation Journal on Optimization and Applications), Vol 1, Issue No. 2, 2021

[10] A.R. Iskandar, dan I.Intias, "Rancang Bangun Online Analytical Processing (OLAP) Classic Model Data." In Seminar Nasional Informatika dan Aplikasinya. 2019.R. Wijaya dan B.Pudjoatmodjo,

[11] "Penerapan Extraction-TransformationLoading (ETL) Dalam Data warehouse (Studi Kasus: Departemen Pertanian)." Jurnal Nasional Pendidikan Teknik Informatika: JANAPATI, vol. 5, no. 2, pp.6175, 2016. 